\title{
CORPO, MÍDIA E STATUS SOCIAL: reflexões sobre os padrões de beleza
}

\section{Body, media and social status: reflection about esthetic patterns}

\author{
Gisele Flor \\ Jornalista, especialista em Design de Multimídia e Mestranda em Comunicação Social pela Universidade Metodista, São Paulo, \\ SP - Brasil, e-mail: giseleflor@gmail.com
}

\section{Resumo}

Este artigo busca avaliar como as revistas femininas têm explorado o padrão de boa forma e beleza em seus conteúdos, relacionando-os ao status social. Propõe-se, a partir da análise da revista feminina Claudia, identificar separadamente os conteúdos relativos à beleza e os relativos à boa forma, verificar quantos deles relacionam beleza e/ou boa forma ao status social, e ainda analisar como o padrão de boa forma e beleza é construído por esse veículo de comunicação. Para a realização da pesquisa utiliza-se a análise de conteúdo, sendo o universo o conteúdo da revista dos meses de julho a novembro de 2009. A amostra são os conteúdos da editoria Beleza e Saúde, que foram divididas em duas categorias: boa forma e beleza, utilizando-se, deste modo, a análise categorial temática. A interpretação dos dados mostrou que dos 29 conteúdos analisados, 28 relacionam beleza e boa forma com status social, na medida em que induzem ao uso de técnicas e produtos de preços elevados para a obtenção de um corpo magro, bonito e saudável. Pode-se deduzir ainda que o padrão de beleza construído pela publicação está associando a magreza com saúde e status social.

Palavras-chave: Beleza. Revistas femininas. Mídia e influência.

\begin{abstract}
This article aims to evaluate how women's magazines have explored fitness and beauty patterns in their contents, relating them to the social status. Based on Claudia magazine, the present study identifies separately the articles related to beauty and fitness, and then verifies how many of them relate beauty or/and fitness to social status. It's also intended to analyze how beauty and fitness patterns are built by this means of communication. The research takes the universe of magazine's contents of July to November 2009. The sample are the contents of Beauty and Health section, which were splited in two subject matter (fitness and beauty), using the analysis category theme. The data interpretation showed that 28 out of the 29 analysed contents relates beauty and fitness to social status, as they persuade to use technique and expensive products to have a thin, beautiful and healthy body.
\end{abstract}

Keywords: Beauty. Women's magazines. Media and influence. 


\section{INTRODUÇÃO}

A preocupação com a boa forma e beleza acompanha a humanidade desde os primórdios. $\mathrm{Na}$ Grécia antiga, valorizava-se o nu masculino e o homem deveria mostrar um corpo forte, exercitado; na Idade Média, ao contrário, o corpo não poderia ser exibido, por causa do misticismo religioso. Já no fim da Idade Medieval começa um culto pelas formas corporais. No Renascimento fazia parte da "disciplina" do corpo aristocrático saber dançare, consequentemente, apresentar um corpo belo. Percebe-se que cada época houve um estereótipo aceitável de boa forma e beleza.

No entanto, por trás da construção dos padrões de boa forma ebeleza esconde-se uma ideologia política, elitista e social. $\mathrm{Na}$ Alemanha nazista, por exemplo, o discurso estético-corporal tinha a função de exaltar o indivíduo que se adequava aos modelos arianos e menosprezava os que não se enquadravam. Contudo, esse fato pode ser observado ainda hoje em nossa sociedade, pois a estética corporal serve como divisor social, na medida em que exclui os que não estão de acordo com os arquétipos difundidos principalmente pelos meios de comunicação de massa.

Segundo Fischler (1995), o corpo constitui nas sociedades contemporâneas uma conduta resultante de coerções sociais. Basta lembrar as situações de desprezo e desprestígio experimentadas pelos obesos e pelas pessoas consideradas feias em nossa sociedade. Essa discriminação se estende em todo o âmbito social, seja para encontrar um emprego, um namorado, ou nos comentários maldosos feitos por outros indivíduos nas ruas e na própria mídia, que ajuda a reforçar os estereótipos de (im)perfeição.

Atualmente, os meios de comunicação de massa têm sido um importante veículo na divulgação e construção dos padrões de beleza e de exclusão social, pois, enquanto dispositivo de poder a serviço de uma comunicação baseada nas fórmulas de mercado, atualiza constantemente as práticas coercitivas que atuam explicitamente sobre a materialidade do corpo. A mídia, por meio dos discursos publicitários e jornalísticos, mostra que para ser considerado belo é necessário ter um corpo perfeito (lê-se magro), e para obtê-lo qualquer sacrifício é válido.

Segundo Denise da Costa Oliveira e Aline Almeida de Faria (2007), são as representações midiáticas que têm o mais profundo efeito sobre as experiências do corpo, reforçam a "autoestima", mostram o poder que a exaltação e exibição dele assumem no mundo contemporâneo.
As revistas femininas, em especial, são meios essenciais para a criação dos padrões estético-corporais: reproduzem imagens de mulheres com o corpo magro, reportagens com atrizes ou modelos contando como conseguem manter a forma e a pele perfeita, especialistas discursando sobre técnicas para "enxugar" as gordurinhas, esteticistas trazendo as últimas novidades sobre cosméticos e personal trainners falando sobre exercícios que ajudam a reduzir medidas.

Denise Bernuzzi de Sant'Anna (2004) reitera a assertiva acima ao afirmar que as revistas femininas são veículos eficazes na difusão social das técnicas estéticas. De acordo com estudo realizado por Jean Charles Zozzoli (2005), mais de três quartos das capas desses veículos de comunicação dirigidas às mulheres têm um título que se refere ao melhor modo de mudar a aparência física.

Fundamentando-se nos pensamentos dos autores anteriormente citados, na observação empírica sobre o comportamento das mulheres com relação à busca pelo corpo perfeito e na constatação de que as revistas femininas vêm divulgando incessantemente métodos e técnicas para atingir esta perfeição, sentiuse a necessidade de aprofundar os estudos sobre a relação entre boa forma, beleza, sociedade e mídia.

Para atingir o patamar de boa forma e beleza divulgado pelas revistas femininas é necessário gastar dinheiro e tempo, mas não são todas as pessoas que estão possibilitadas a investir nos cuidados com a aparência, apenas as que possuem recursos financeiros.

Inês Senna Shaw (2003) mostra como o conceito de beleza não pode deixar de ser associado com o poder financeiro e cultural que o indivíduo ocupa na esfera pública. Pierre Bordieu (2001) também explica como o corpo e as práticas corporais estão investidos de significados que refletem a condição econômica do indivíduo. Dessa forma, pode-se questionar se essas mensagens apresentam conteúdos que relacionam boa forma e beleza com status social.

Essas relações entre boa forma e beleza, classe social e status, com o crescimento da indústria da beleza e da sociedade capitalista-consumista, tornamse mais evidentes, pois não apenas os cosméticos e as cirurgias, mas também dietas e exercícios adquirem um valor simbólico de prestígio. Essa relação é sustentada por Max Weber (1971), a a afirmar que nas sociedades capitalistas a propriedade de alguns bens materiais e as possibilidades de usá-los são determinantes para classificar as pessoas em posições sociais.

A afirmação de Pierre Bordieu também ajuda a compreender os processos de identificação 
de grupos sociais de acordo com padrões estabelecidos culturalmente, pois para ele a disposição estética constitui-se como "una expresión distintiva de una posición privilegiada em el espacio social, cuyo valor distintivo se determina objectivamente en la relación com expresiones engendradas a partir de condiciones diferentes" (BORDIEU, 1998, p. 53).

Featherstone (1999) reitera que os processos de distinção social surgem com a cultura de consumo, ao afirmar que

se é possível afirmar o funcionamento de uma lógica do capital derivada da produção, talvez seja possível afirmar também uma "lógica do consumo", que aponta para os modos socialmente estruturados de usar bens para demarcar relações sociais (FEATHERSTONE, 1999, p. 35).

Importante ressaltar que o estudo dos padrões de boa forma e beleza está relacionado com corpo e classe social. Segundo Foucault (1987), a análise do corpo é elemento essencial para a compreensão das estruturas sociais e suas relações de poder. Desse modo, pretende-se com este estudo enriquecer as análises sobre o efeito da mídia na sociedade e a relação da boa forma e beleza com a classe social.

Assim, é necessário proceder a uma análise crítica, com uma postura atenta e questionadora, sobre as informações que são veiculadas nas revistas femininas, problematizando os conteúdos sobre boa forma e beleza.

A escolha do objeto de estudo, a revista feminina Claudia, da Editora Abril, se deve ao fato de ser destinada a este público, estar há 48 anos no mercado e contemplar na linha editorial assuntos de interesse feminino, tais como saúde, boa forma, sexo, familia, casa e beleza. A preferência pelo período analisado pode ser justificada pelas edições abordarem com mais ênfase a temática da beleza e boa forma por causa da mudança de estação inverno/primavera/verão. Outro fator determinante para a opção do objeto foi o preço do veículo de comunicação, considerado elevado para as classes mais baixas - o que já a põe como uma mídia destinada a mulheres com algum poder aquisitivo, embora não a torne inacessível às de classes baixas.

Stéphane Malysse (2002) relata que as revistas femininas propagam o estilo de vida da classe dominante, mas não deixam de ser lidas pelas outras classes, por conta da circulação dos meios de comunicação, uma vez que as mulheres que não têm como pagar por elas podem encontrar essas publicações em consultórios médicos ou odontológicos, salões de beleza e nas casas das patroas.

Este estudo conduz à clássica discussão sobre a relação mídia-sociedade no mundo contemporâneo, na medida em que toca no debate acerca da autonomia individual diante das imposições ditadas pelos meios de comunicação. Tratar o tema boa forma e beleza é também falar em corpo; consequentemente, falar em corpo remete a questões sociais. Assim, pode-se justificar a importância da pesquisa, pois busca compreender o papel da mídia na construção de padrões estéticos e sua relação com status social e sociedade. $\mathrm{O}$ estudo tambéméimportante, uma vez que as pesquisas sobre a relação mídia-sociedade contribuem para a compreensão dos fenômenos sociais. Dessa forma, torna-se necessário revelar o conteúdo sobre boa forma e beleza difundido pelas revistas femininas, que emoldura o comportamento das mulheres na busca pelo corpo ideal e a sua relação com classe social.

Para realizar o presente estudo utilizou-se para a coleta de dados a análise de conteúdo, com uma abordagem qualitativa e categorial temática, tendo como unidade de registro o tema boa forma e beleza, e para a interpretação dos resultados, a codificação foi realizada com base em um formulário (Tabela 1) com os seguintes pontos:

TABELA 1 - Formulário para análise de conteúdo sobre o tema forma e beleza

\begin{tabular}{lllc}
\hline $\mathbf{1}$ Temática do conteúdo & Boa Forma & Saúde & Beleza \\
\hline $\mathbf{2}$ Conotação do conteúdo & Mensagem ligada a status social & Mensagem neutra & Informativa \\
$\mathbf{3}$ Conteúdo da mensagem & Boa forma & Saúde & Beleza \\
$\mathbf{4}$ Conteúdo da mensagem sobre boa forma & Magreza e beleza & Magreza e status social & Magreza e saúde \\
$\mathbf{5}$ Conteúdo da mensagem sobre saúde & Status social & Saúde & Beleza \\
$\mathbf{6}$ Conteúdo da mensagem sobre beleza & Status social & Saúde & Beleza \\
$\mathbf{7}$ Motivação dos cuidados com o corpo & Status social & Saúde & Beleza \\
\hline
\end{tabular}


A escolha da análise de conteúdo se justifica pelo fato de ser indicada para detectar tendências de noticiabilidade, agendamentos, enquadramentos, descrever e classificar produtos, gêneros e formatos jornalísticos, além de ajudar a entender o processo de divulgação e recepção das mensagens.

\section{DESCRIÇÃO DO OBJETO}

A revista Claudia é uma publicação da Editora Abril e está há 48 anos no mercado, abordando o dia a dia da mulher, como relacionamentos, as grandes mulheres que fizeram história, família, filhos, carreira, sucesso, dinheiro, moda, beleza, saúde, etc., além de temas atuais. A mídia possui em média 190 páginas e está dividida nas seguintes editorias: Família e Filhos, Casa e Consumo, Atualidade Gente, Beleza e Saúde, Moda, Emoções e Espiritualidade, Sempre em Claudia, com um público-alvo composto por mulheres de classe média alta, entre 25 e 45 anos, que trabalham fora e tem uma vida familiar ativa.

\section{Corpo como valor simbólico}

Para que a pesquisa proposta seja desenvolvida, trabalha-se com os conceitos de classe social, status, corpo, consumo, beleza, mídia e influência.

Antes de entrar na questão do corpo, definese primeiramente o que é classe social. Karl Marx (1988) afirma que as classes constituem a estrutura de uma sociedade. O sociólogo não as define com base na renda ou na origem de seus rendimentos, mas de acordo com a propriedade dos meios de produção.

Robert Henry Srour (1987) fornece a fundamentação, uma vez que classifica as classes sociais em camadas, ou seja, de acordo com a escala de rendimento: altas, médias e baixas. A definição de status social se torna necessária nesse ponto, pois é elementar para que se possa entender o conjunto social, uma vez que o conceito de status está intimamente relacionado com classe social e sua relação com a sociedade.

Para Raymond Boudon e Baechler (1995), status social diz respeito à honra social ou ao prestígio que o indivíduo ocupa na sociedade, uma vez que está fundado em juízos de valor e avaliações feitas pelos membros da comunidade. $\mathrm{O}$ autor ainda ressalta que uma forma de determinar o status de uma pessoa é observar seus hábitos, estilo de vida, profissão, nível de instrução, posse de objetos e os relacionamentos, uma vez que os grupos e relacionamentos tendem a ser formado por pessoas do mesmo padrão social.

Pierre Bordieu (1998) sustenta que o status seria a possibilidade de desfrutar certos bens simbólicos, pois estes determinam de certa maneira a classe social que o indivíduo ocupa. Segundo o sociólogo, os bens simbólicos são instrumentos de conhecimento, comunicação e integração social, podem ser apropriados pelo conjunto de um grupo ou produzidos por especialistas, determinando o status. Para Srour (1987), os bens simbólicos podem ser livros, revistas, restaurantes, carros e até as mensagens que estão na mídia.

$\mathrm{Na}$ sociedade moderna o corpo também adquire um valor simbólico, na medida em que ele também é um identificador de classe social. Segundo Goldenberg (2002), o corpo é um agente das diferenças sociais e, sendo "cultivado sob a moral da boa forma, surge como marca indicativa de certa virtude superior daquele que o possui. Um corpo coberto de signos distintos que, mesmo nu, exalta e torna visíveis as diferenças entre grupos sociais" (GOLDENBERG, 2002, p. 10).

Bourdieu aponta para a linguagem corporal como marcador de distinção social:

O corpo é a mais irrecusável objetivação do gosto de classe, que se manifesta de diversas maneiras. Em primeiro lugar, no que tem de mais natural em aparência, isto é, nas dimensões (volume, estatura, peso) e nas formas (redondas ou quadradas, rígidas e flexíveis, retas ou curvas, etc...) de sua conformação visível, mas que expressa de mil maneiras toda uma relação com o corpo, isto é, toda uma maneira de tratar o corpo, de cuidá-lo, de nutri-lo, de mantê-lo, que é reveladora das disposições mais profundas do habitus (BOURDIEU, 2001, p. 188).

Para Malysse (2002), o "corpo natural" é sinônimo do corpo social, na medida em que se torna metáfora da sociedade, encarnando desigualdades sociais de acesso às construções corporais. A afirmação de Pierre Bordieu (2001) torna mais claros os argumentos de Malysse. Segundo o autor, a sociedade capitalista e burguesa legitima seu poder econômico-social por meio da criação de arquétipos e produtos que contribuem para que haja uma nítida delimitação entre ricos e pobres. 
Essa delimitação é também construída através do consumo. Roland Barthes (1980) aponta que o consumo possui duplo aspecto: satisfazer às necessidades materiais e carregar estruturas $\mathrm{e}$ símbolos sociais e culturais, aspectos que considera inseparáveis. Guy Debord (1997) afirma que o caráter prestigioso de um objeto se deve a ter ele sido colocado no centro da vida social.

A assimilação das mercadorias com prestígio social e financeiro é realizada com base no poder econômico e cultural. Bordieu (1998) argumenta que o capital econômico é também um capital cultural, e os hábitos relacionados aos cuidados com o corpo e os padrões estéticos permitem identificar a origem social do indivíduo. O sociólogo explica que, com o advento da sociedade de consumo, a diferenciação de classe baseada nos conceitos de beleza se torna ainda mais evidente.

A explicação de Featherstone (1995) é fundamental para a compreensão da relação entre sociedade de consumo e questão social, pois mostra como as mercadorias proporcionam prestígio social e serve para delimitar a classe social do indivíduo:

Usar a expressão cultura de consumo significa enfatizar que o mundo das mercadorias e seus princípios de estruturação são centrais para a compreensão da sociedade contemporânea. Isso envolve um foco duplo: em primeiro lugar, na dimensão cultural da economia, a simbolização e o uso de bens materiais como "comunicadores", não apenas como utilidades; em segundo lugar, economia dos bens culturais, os princípios de mercado - oferta, demanda, acumulação de capital, competição e monopolização - que operam dentro da esfera dos estilos de vida, bens culturais e mercadorias (FEATHERSTONE, 1995, p. 127).

Para Karl Marx (1988), a mercadoria é também a forma elementar da riqueza capitalista, tem a propriedade de satisfazer todas as necessidades do ser humano e adquire um valor de uso quando se realiza o consumo. Desse modo, pode-se compreender como os cosméticos, as cirurgias, as academias e os personal trainners, na sociedade capitalista da boa forma e beleza, são utilizados para criar vínculos e/ ou para estabelecer distinções sociais.

Na mídia, a experiência do corpo se confunde com a de consumo. Mike Featherstone explica que, para a mídia, a mensagem da boa forma e beleza é algo que produz lucro; desta forma o assunto é propagado em todos os veículos de comunicação exaustivamente. Produtos, técnicas, dietas e exercícios físicos são citados exaustivamente como meios para obter o almejado corpo perfeito, mas para conseguir atingir este patamar é preciso consumir alguns destes dispositivos. Desse modo, não é apenas a busca pela saúde e beleza que faz com que pessoas gastem fortunas para ter o corpo ideal, mas também pelo status que ele proporciona, uma vez que ele é um meio de representação social.

Siqueira e Faria (2007) reiteram que nos meios de comunicação de massa a experiência do corpo se confunde com a de consumo. Segundo elas, "não é o espetáculo do martírio que interessa (os suplícios e as dificuldades para alcançar o corpo modelo), mas o espetáculo do resultado das transformações (a conversão do corpo), ou seja, o corpo convertido ao modelo é o espetáculo" (SIQUEIRA; FARIA, 2007, p. 179).

Garrini (2007) enfatiza que os meios de comunicação social colocam o consumo como agente motivador para obter as formas físicas desejadas e ainda exaltam os bens simbólicos destinados para o tratamento da boa forma e beleza.

Fontanella (2005) diz que na cultura de consumo o corpo serve como elemento para exclusão, pois os indivíduos que não estão de acordo com os estereótipos são colocados em situações de constrangimentos, principalmente por meio da mídia.

\section{Mídia e influência}

A discussão sobre o poder de controle dos meios de comunicação tem na reflexão de Adorno e Horkheimer (1985) e Harold Laswell (2006 apud WOLF, 2006) as principais referências teóricas. Os autores apontam a influência das mídias, seus efeitos, bem como sua relação com a indústria cultural, no que se refere à difusão de valores estéticos impostos à sociedade.

Adorno e Horkheimer (1985) afirmam que os meios de comunicação de massa impõem padronização, e uma das táticas utilizadas para que as pessoas sigam os modelos é utilizar estereótipos. Laswell (2006 apud WOLF,2006), emuma de suas premissas, sustenta que a comunicação na mídia é intencional e orientada para obter um efeito nos indivíduos. Segundo Santos e Serra (2003), o poder da mídia está em produzir sentidos, projetá-los e legitimá-los. 
Para Castro (2001), os meios de comunicação são importantes difusores de um ideal de beleza a ser alcançado, na medida em que garante que a temática esteja sempre presente, levando ao receptor as últimas novidades sobre o assunto, ditando e incorporando tendências, e as revistas femininas são um dos meios.

Conforme Moraes (2006), as revistas femininas ensinam qual o corpo que as mulheres devem ter e desejar, além de ensinar a atingir o ideal e como utilizá-lo. Dessa forma, percebe-se que os modelos de beleza que a sociedade tem atualmente são os estipulados pela mídia, que é um corpo magro e bem torneado, além dos seios e do bumbum volumosos para as mulheres e um corpo musculoso para os homens.

\section{ANÁLISE DA PESQUISA}

Para realizar o presente estudo utilizou-se uma pesquisa qualitativa com análise de conteúdo, sendo o universo de pesquisa a amostra dos conteúdos sobre beleza e boa forma da editoria Beleza e Saúde publicados na revista Claudia entre julho a novembro de 2009, que correspondem respectivamente às edições 574, 575, 576, 577 e 578.

Primeiramente, foram identificados os conteúdos relativos à beleza em todas as cinco edições da revista, e pôde-se constatar que há em média de três a quatro matérias e dicas sobre o assunto em cada edição. Dessa forma, somou-se um total de 20 conteúdos sobre a temática. A análise do quadro analítico proposto para a codificação da pesquisa mostrou que todos os 20 conteúdos estão relacionados com status, pois apresentam uma mensagem que relaciona beleza com posição social, ao indicar produtos com preços elevados, técnicas com altos custos para deixar a pele e o corpo mais bonitos e saudáveis, além de dietas com alimentos também de preços não acessíveis a todos.

A profissão das entrevistadas ainda revela a mensagem conotativa de status social elevado, pois muitas delas são mulheres com uma carreira sólida, têm bons salários e educação até o terceiro grau. Suas profissões também as associam ao status, tais como advogadas, funcionárias públicas, jornalistas, dentistas e atrizes. Os conteúdos mostram ainda que os cuidados com a beleza são motivados para alcançar não só a "perfeição" física, mas também reconhecimento de independência emocional e financeira, força de vontade e sedução.

É importante ressaltar que na edição 578 há um especial com várias atrizes brasileiras, que dão suas dicas de boa forma, saúde, alimentação e beleza, e indicam técnicas, produtos e dietas que não são acessíveis a todas as mulheres, por terem preço elevado. Após identificar os conteúdos relativos à beleza, foram analisados os relacionados à boa forma, que podem ser encontrados também na editoria Beleza e Saúde. As dicas e reportagens sobre saúde, na verdade, são mais sobre boa forma. Apenas uma teve caráter informativo, sem nenhuma associação com status social. Foram registradas apenas nove mensagens sobre a temática, mas oito relacionando boa forma com status social, ao indicar técnicas para emagrecimento, dietas e exercícios físicos que demandam investimentos não muito baixos.

Os conteúdos relacionados com boa forma também mostraram a mesma tendência dos de beleza, ou seja, a profissão das entrevistadas revela a mensagem conotativa de condição social elevada, dicas de atrizes e personal trainners com exercícios que exigem uma academia para serem realizados. O cuidado com a boa forma não é motivado apenas pela saúde, mas também pela boa aparência física, o prestígio social de ostentar um corpo magro, persistência, determinação, e por se enquadrar no estereótipo ditado pela mídia e aceito pela sociedade.

De acordo com a análise da codificação, podese constatar que, além dos conteúdos estarem voltados para a questão do status social, ainda há uma exaltação à magreza: neste corpo magro há uma mulher forte, determinada, bonita e rica, fato presente em todas as edições analisadas. A apreciação dos conteúdos também constatou que o veículo de comunicaçãoé especialmente voltado para mulheres das classes médias e altas.

No mês de outubro, por exemplo, na editoria de Beleza, a chamada da matéria dizia "Os melhores cremes preenchedores de rugas: produtos que prometem diminuir rugas e sulcos, sem picadas e sem dor". Outra matéria que relaciona status social e boa forma é "Três meses para entrar em forma", na edição de agosto. No conteúdo da reportagem são dados conselhos para cada mês - dietas, tratamentos estéticos e exercícios físicos -, mas todos estes passos, além de exigirem disciplina, ainda requerem dinheiro, uma vez que os métodos são de alto custo.

Outro ponto que merece destaque é a questão do consumo. Ao fornecer dicas sobre produtos 
para beleza, estética e nutrição, há ainda a conotação do consumismo. Se a mulher deseja parecer com uma atriz, ter o corpo, a pele e o cabelo de determinada modelo, ela precisa usar o produto que a referida usa.

Dessa forma, percebe-se que a revista constrói um padrão de boa forma e beleza centrado na classe social que o indivíduo ocupa e no corpo que ostenta, pois, ao recomendar técnicas e produtos de preço elevado, está sugerindo que apenas as pessoas com alto poder aquisitivo podem ser bonitas e magras, pois elas têm condição para usufruir dos produtos e o corpo saudável é o magro.

A forma como a revisa Claudia apresenta os padrões de beleza, corpo magro e saudável, reflete na sociedade a concepção da construção do estereótipo do que é belo. Dessa forma, principalmente as mulheres buscam a qualquer preço se adequar a este padrão; no entanto, algumas técnicas ou dietas podem trazer consequências graves para a saúde e até mesmo para o corpo, se feitas de modo errado.

\section{CONSIDERAÇÕES FINAIS}

A análise mostra que a mídia, por meio de seu discurso, impõe na sociedade os padrões de beleza e boa forma e ainda os relaciona com status social. Alguns títulos fazem apologia ao desprezo do que está fora do estereótipo, e, deste modo, muitos indivíduos passam a acreditar nestes arquétipos e buscam a todo custo atingir o corpo ideal para serem aceitos na sociedade.

Adorno e Horkheimer afirmam que quanto mais forte ficam os estereótipos, mais difícil para as pessoas mudarem de opinião sobre determinado assunto. Assim são com os padrões de boa forma e beleza. A mídia repete incessantemente que ser belo é ser magro e, implicitamente, ser belo, magro, é ser de boa condição social, pois o indivíduo pode pagar uma academia, fazer lipoaspiração, dieta e comprar cosméticos caros. Dessa forma, o padrão de beleza construído pela mídia pode ser resumido em magreza e riqueza.

Além de enaltecer o corpo e fazer dele distintivo de classe social, o discurso das revistas femininas contribuem para que a indústria da beleza aumente seus lucros e a sociedade continue ainda mais consumista - pois a cada dia surge um novo creme, um novo redutor de estrias e celulites, uma nova técnica para reduzir medidas.
Desse modo, o presente trabalho se encerra não com uma conclusão, mas sim com uma reflexão sobre o papel da mídia na construção de estereótipos sociais, pois, com seus discursos, os meios de comunicação contribuem para a estigmatização e o preconceito contra quem não se enquadra nos padrões ditados por eles mesmos, favorecendo ainda para a baixa autoestima dessesindivíduos e a segregação social entre belos e feios, magros e gordos, ricos e pobres.

\section{REFERÊNCIAS}

ADORNO, T.; HORKHEIMER, M. Dialética do esclarecimento. Rio de Janeiro: Zahar, 1985.

BARTHES, R. Sistema da moda. São Paulo: Cia Editora Nacional/EDUSP, 1980.

BOUDON, R. et al. Tratado de sociologia. Rio de Janeiro: Jorge Zahar, 1995.

BOURDIEU, P. La distinción: critérios y bases sociales del gusto. Madrid: Taurus, 1988.

O poder simbólico. 4. ed. Rio de Janeiro: Bertrand Brasil, 2001.

A economia das trocas simbólicas. 5. ed. São Paulo: Perspectiva,1998.

CASTRO,A.L.Corpo,consumoemídia.2001.Disponível em: <http://lakh.unm.edu/handle/10229/51201>. Acesso em: 11 jul. 2009.

DEBORD, G. A sociedade do espetáculo. Rio de Janeiro: Contraponto, 1997.

FEATHERSTONE, M. Cultura de consumo e pósmodernismo. São Paulo: Studio Nobel, 1995.

Cultura global: nacionalismo, globalização e modernidade. 3. ed. Petrópolis: Vozes, 1999.

FISCHLER, C. Obeso benigno, obeso maligno. In: SANTANnA, D. B. (Org.). Políticas do corpo. São Paulo: Estação Liberdade, 1995. p. 68-80.

FONTANELLA, F. I. A estética do brega: cultura de consumo e o corpo nas periferias do Recife. 2005. 112 f. Dissertação (Mestrado em Comunicação Social) Universidade Federal de Pernambuco, Pernambuco, 2005.

FOUCAULT, M. Vigiar e punir. Petrópolis: Vozes, 1987. 
GARRINI, S. P. F. Do corpo desmedido ao corpo ultramedido: reflexões sobre o corpo feminino e suas significações na mídia impressa. In: CONGRESSO NACIONALDE HISTORIA DA MÍDIA, 5., 2007, Received: 11/10/2009

São Paulo. Anais... São Paulo: Intercom, 2007.

Aprovado: 19/11/2009

Approved: 11/19/2009

GOLDEMBERG, M. A civilização das formas: o corpo como valor. In: GOLDENBERG, M. (Org.). Nu e vestido. Rio de Janeiro: Record, 2002. Revisado: 18/01/2010 p. 139-188.

MALYSSE, S. Em busca dos (H)alteres-ego: olhares franceses nos bastidores da corpolatria carioca. In: GOLDENBERG, M. (Org.). Nu e vestido. Rio de Janeiro: Record, 2002. p. 79-138.

MARX, K. O capital: crítica da economia política. Livro 3. São Paulo: Bertrand, 1988.

MAUSS, M. Técnicas corporais. In: Sociologia e antropologia. São Paulo: EDUSP, 1974. p.209-239.

NOVAES, J. V. O intolerável peso da feiúra: sobre as mulheres e seus corpos. Rio de Janeiro: Garamond, 2006.

SANT'ANNA, D. B. Cultos e enigmas do corpo na história. In. STREY, M. N.; CABEDA, S. T. L. (Org.). Corpos e subjetividade em exercício. Porto Alegre: EDIPUCRS, 2004. p. 81-91.

SANTOS, E. M.; SERRA, G. M. A. Saúde e mídia na construção da obesidade e do corpo perfeito. Ciência e Saúde Coletiva, v. 8, n. 3, p. 691-701, 2003.

SHAW, I. S. O corpo feminino na propaganda. In: BERNADETTE, L.; SANTANA, G. (Org.). Corpo e mídia. São Paulo: Arte \& Ciência, 2003. p. 193-206.

SIQUEIRA, D. C. O.; FARIA, A. A. Corpo, saúde e beleza: representações sociais nas revistas femininas. Comunicação, mídia e consumo, v. 4, n. 9, mar. 2007.

SROUR, R. H. Classes, regimes, ideologias. São Paulo: Ática, 1987.

ZOZZOLI,J-Ch.J. Corpos de mulheres enquanto marcas na mídia: recortes. In: BRANDÃO, I. (Org.). O corpo em revista. Maceió: Edufal, 2005. p. 47-82.

WEBER, M. Classe, estamento, partido. In:

Ensaios de sociologia. Rio de Janeiro: Zahar, 1971. p. 211-221.

WOLF, M. Teorias da comunicação. Lisboa: Presença, 2006. 